\title{
Tingkat Pengetahuan Ibu Nifas tentang Kolostrum dengan Motivasi Pemberian Kolostrum di Rumah Sakit Panembahan Senopati Bantul, Yogyakarta
}

\author{
Desti Astuti ${ }^{1}$, Anafrin Yugistyowati ${ }^{2}$, Oktaviana Maharani ${ }^{3}$ \\ 1,2,3 Sekolah Tinggi IImu Kesehatan Alma Ata Yogyakarta \\ Jalan Ringroad Barat Daya No 1 Tamantirto, Kasihan, Bantul, Yogyakarta
}

\begin{abstract}
Abstrak
Pada tahun 2012 cakupan air susu ibu (ASI) eksklusif di DIY yaitu 48\%, sedangkan di Kabupaten Bantul sebanyak 62,05\% pada tahun 2013. ASI yang pertama kali keluar setelah melahirkan disebut kolostrum dan sangat penting diberikan kepada bayi, namun banyak ibu nifas yang kurang atau tidak mengetahui tentang pentingnya kolostrum. Tujuan penelitian untuk mengetahui hubungan tingkat pengetahuan ibu nifas tentang kolostrum dengan motivasi pemberian kolostrum di Rumah Sakit Panembahan Senopati Bantul Yogyakarta. Jenis penelitian observasional dengan pendekatan cross sectional. Sampel 54 orang ibu nifas hari ke 0-4 di Rumah Sakit Panembahan Senopati Bantul Yogyakarta dengan tekhnik Accidental Sampling. Instrumen penelitian dengan kuesioner tertutup. Teknik analisis data dengan Kendall Tau. Hasil penelitian statistik menggunakan uji korelasi Kendal Tau diperoleh p-value sebesar 0,000<a $(0,05)$. Nilai koefisien korelasi sebesar 0,632 yang menunjukkan tingkat hubungannya adalah kuat. Kesimpulan terdapat hubungan tingkat pengetahuan ibu nifas tentang kolostrum dengan motivasi pemberian kolostrum di Rumah Sakit Panembahan Senopati Bantul Yogyakarta tahun 2015.
\end{abstract}

Kata Kunci: tingkat pengetahuan, kolostrum, motivasi pemberian kolostrum

\section{The Knowledge Level of Postpartum Mothers about Colostrum and Her Motivation of Colostrum Giving in Panembahan Senopati Bantul Hospital, Yogyakarta}

\begin{abstract}
In 2012 the scope of exclusive breastfeeding in DIY were 48\%, while in Bantul district as much as $62.05 \%$ in 2013. Breastfed which is first out after delivery called colostrum and very important given to infants, but many of postpartum mothers are less or not knowing about the importance of colostrum. The purpose of study was to know relationship between the knowledge level of postpartum mothers about colostrum and motivation of giving colostrum in Panembahan Senopati Bantul hospital, Yogyakarta. This study was an observational analytic with cross sectional design. Samples were 54 of postpartum mothers days 0 to 4 at Panembahan Senopati Bantul hospital, Yogyakarta which obtained by accidental sampling technique. Instruments used was closed questionnaire. Data analysis used Kendal Tau test. The data were analyzed by statistical correlation kendall tau obtained $p$-value were $0.000<\alpha(0.05)$. The value of a correlation coefficient were 0.632 . it mean that the connection was strong. In conclusions, there was a relationship between knowledge level of pospartum mothers about colostrum and motivation of giving colostrum in Panembahan Senopati Bantul hospital, Yogyakarta 2015.
\end{abstract}

Keywords: colostrum, knowledge level, motivation

Info Artikel:

Artikel dikirim pada 18 Oktober 2015

Artikel diterima pada 20 Oktober 2015 


\section{PENDAHULUAN}

Derajat kesehatan masyarakat Indonesia ditentukan oleh banyak faktor, tidak hanya ditentukan oleh pelayanan kesehatan dan ketersediaan sarana dan prasarana kesehatan, namun juga dipengaruhi faktor ekonomi, pendidikan, lingkungan sosial, keturunan, dan faktor lainnya. Faktor-faktor ini berpengaruh pada kejadian morbiditas, mortalitas dan status gizi di masyarakat. Angka morbiditas, mortalitas dan status gizi dapat menggambarkan keadaan dan situasi derajat kesehatan masyarakat(1).

Salah satu upaya untuk meningkatkan sumber daya manusia antara lain dengan jalan memberi Air Susu Ibu (ASI) sedini mungkin(2). World Health Organization (WHO) menjelaskan bahwa ASI adalah makanan ideal untuk pertumbuhan dan perkembangan bayi. ASI merupakan makanan pertama, utama, dan terbaik bagi bayi yang bersifat alamiah. ASI mengandung berbagai zat gizi yang dibutuhkan dalam proses pertumbuhan dan perkembangan bayi baru lahir yang akhirnya bertujuan untuk menurunkan angka kematian bayi $(A K B)(3)$.

Pada tahun 2010 WHO merevisi rekomendasi global mengenai pemberian ASI yang harus dilakukan sesegera mungkin, yaitu dalam waktu satu jam setelah bayi lahir dan dianjurkan memberikan ASI eksklusif selama 6 bulan(4). Data Profil Kesehatan Indonesia Tahun 2013 menunjukan bahwa persentase pemberian ASI eksklusif pada bayi 0-6 bulan di Indonesia sebesar 61,5\%(5). Tahun 2012 cakupan ASI Eksklusif di provinsi DIY yaitu 48\%(6). Cakupan ASI eksklusif di kabupaten Bantul pada tahun 2013 yaitu $62,05 \%(7)$.

ASI eksklusif adalah pemberian ASI selama 6 bulan tanpa tambahan cairan lain, seperti susu formula, jeruk, madu, air teh, dan air putih, serta tanpa tambahan makanan padat, seperti pisang, bubur susu, biskuit, bubur nasi, dan nasi tim, kecuali vitamin dan mineral dan obat(8). Pemberian ASI pada satu jam pertama setelah rnelahirkan dapat mempercepat pergantian produksi susu dari payudara yang penuh dan matang. Sentuhan kulit antara ibu dan bayi, serta isapan bayi akan membantu memperlancar produksi ASI(9).

Pemberian kolostrum dapat dimulai sejak satu jam pertama bayi dilahirkan dengan melakukan praktik inisiasi menyusu dini (IMD). Pendekatan IMD yang sekarang dianjurkan adalah dengan metode breast crawl (merangkak mencari payudara) dimana setelah bayi lahir segera diletakkan di perut ibu dan dibiarkan merangkak untuk mencari sendiri puting ibunya dan akhirnya menghisapnya tanpa bantuan(10).

Beberapa pendapat yang menghambat ibu nifas memberikan kolostrum dengan segera, diantaranya takut bayi kedinginan, setelah melahirkan ibu terlalu lelah untuk menyusui bayinya, kolostrum tidak keluar atau jumlah kolostrum tidak memadai, serta kolostrum tidak baik dan berbahaya bagi bayi. Hal di atas tidak akan terjadi jika seorang ibu nifas mempunyai pengetahuan yang bagus serta mendapat dukungan dari keluarga(8).

Berdasarkan data Rumah Sakit Panembahan Senopati Bantul Yogyakarta tahun 2014 jumlah pasien melahirkan sebanyak 1.159 orang, dan rata-rata ibu nifas tiap bulan di Ruang Alamanda III Rumah Sakit Panembahan Senopati Bantul sebanyak 114 orang. Hasil survey awal yang dilakukan peneliti kepada 11 orang pasien ibu nifas di Rumah Sakit Panembahan Senopati Bantul, didapatkan data bahwa 6 orang ibu mengetahui tentang kolostrum serta memberikan kepada bayinya; sedangkan 5 orang ibu tidak mengetahui tentang kolostrum dan tidak memberikan kepada bayinya. Menurut ibu hal ini dilakukan karena tidak mengetahui manfaat kolostrum bagi bayi.

Tujuan penelitian ini untuk mengetahui hubungan tingkat pengetahuan ibu nifas tentang kolostrum dengan motivasi pemberian kolostrum di Rumah Sakit Panembahan Senopati Bantul Yogyakarta tahun 2015.

\section{BAHAN DAN METODE}

Jenis penelitian ini adalah penelitian analitik atau induktif observasional. Desain yang digunakan dalam penelitian ini berupa rancangan cross sectional. Populasi dalam penelitian adalah semua ibu nifas di Ruang Alamanda III Rumah Sakit Panembahan Senopati Bantul Yogyakarta tahun 2015. Teknik pengambilan sampel menggunakan accidental sampling. Sampel penelitian diambil dengan kriteria inklusi: ibu nifas di Rumah Sakit Panembahan Senopati Bantul Yogyakarta pada hari pertama sampai ke empat, ibu nifas yang mampu komunikasi lancar dengan bahasa Indonesia atau bahasa Jawa, ibu nifas yang bisa menulis dengan benar, ibu nifas yang bersedia menjadi responden penelitian. Kriteria eksklusi penelitian yaitu: Ibu dari bayi lahir dengan kelainan kongenital yang 
tidak memungkinkan bayi untuk disusui, seperti labiopalatoskisis dan atresia esophagus, ibu nifas dengan penyakit infeksi dan komplikasi persalinan misalnya AIDS, hepatitis, dan perdarahan, dan ibu dari bayi yang mengalami asfiksia, sianosis, atau gejala sesak nafas. Sampel dihitung menggunakan rumus Slovin didapatkan 54 resoponden penelitian.

Instrumen penelitian berupa kuesioner yang telah diuji validitas dan reliabilitas di RSUD Majenang terhadap 20 butir pertanyaan yang digunakan dalam penelitian. Analisa data menggunakan analisis univariat dan bivariat dengan uji kendall tau. Selain itu, variabel bebas penelitian ini yaitu tingkat pengetahuan ibu nifas tentang kolostrum; sedangkan variabel terikat penelitian ini yaitu motivasi pemberian kolostrum.

\section{HASIL DAN BAHASAN}

\section{Hasil Analisa Data Univariat}

\section{Karakteristik Responden}

Berdasarkan kelompok umur, maka dapat diketahui distribusi frekuensi responden pada Tabel 1.

Tabel 1. Distribusi Frekuensi Karakteristik Ibu Nifas Berdasarakan Umur di Rumah Sakit Panembahan Senopati Bantul

\begin{tabular}{lcc}
\hline \multicolumn{1}{c}{ Umur } & f & \% \\
\hline$<20$ tahun & 5 & 9,3 \\
20-35 tahun & 40 & 74,1 \\
$>35$ tahun & 9 & 16,7 \\
Total & 54 & 100 \\
\hline
\end{tabular}

Sumber: Data Primer 2015

Berdasarkan Tabel 1 tersebut dapat diketahui bahwa sebagian besar responden berumur antara 20-35 tahun yaitu sebanyak 40 orang $(74,1 \%)$. Usia mempengaruhi terhadap daya tangkap dan pola pikir seseorang, semakin bertambah usia akan semakin berkembang pula daya tangkap dan pola pikirnya, sehingga pengetahuan yang diperolehnya semakin membaik(11). Pendapat ini sejalan dengan penelitian Kusmayanti yang menyatakan bahwa semakin meningkat umur seseorang maka persentase pengetahuannya semakin baik(12).

Distribusi frekuensi karakteristik ibu nifas berdasarkan pendidikan dapat dilihat pada Tabel 2 .
Tabel 2. Distribusi Frekuensi Karakteristik Ibu Nifas Berdasarkan Pendidikan di RSUD Panembahan Senopati Bantul

\begin{tabular}{lcc}
\hline \multicolumn{1}{c}{ Pendidikan } & f & \% \\
\hline SD & 7 & 13,0 \\
SMP & 17 & 31,5 \\
SMA & 28 & 51,9 \\
Perguruan Tinggi & 2 & 3,7 \\
Total & 54 & 100 \\
\hline
\end{tabular}

Sumber: Data Primer Tahun 2015

Tabel 2 menunjukkan bahwa mayoritas responden dengan latar belakang pendidikan SMA yaitu sebanyak $(51,9 \%)$ atau 28 responden. Semakin tinggi pendidikan seseorang maka akan semakin mudah dalam menerima informasi dan semakin banyak pengetahuan yang dimiliki sehingga mempengaruhi perilaku seseorang(13). Sesuai dengan penelitian Tarigan, tentang pemberian kolostrum bagi bayi baru lahir pada suku Karo di Desa Sukanalu Kecamatan Barusjahe, penelitian menunjukkan bahwa ada hubungan yang bermakna antara tingkat pendidikan ibu terhadap perilaku pemberian kolostrum(14).

Berdasarkan jenis pekerjaan responden maka dapat diketahui distribusi frekuensi responden dilihat pada Tabel 3.

Tabel 3. Distribusi Frekuensi Karakteristik Ibu Nifas Berdasarkan Jenis Pekerjaan di RSUD Panembahan Senopati Bantul

\begin{tabular}{lcc}
\hline \multicolumn{1}{c}{ Pekerjaan } & f & \% \\
\hline IRT & 35 & 64,8 \\
Buruh & 8 & 14,8 \\
Wiraswasta & 8 & 14,8 \\
Pedagang & 1 & 1,9 \\
Petani & 2 & 3,7 \\
Total & 54 & 100 \\
\hline
\end{tabular}

Sumber: Data Primer Tahun 2015

Berdasarkan Tabel 3 menunjukkan bahwa sebagian besar responden tidak bekerja atau hanya sebagai ibu rumah tangga yaitu sebanyak 35 orang $(64,8 \%)$.

Semakin tinggi pekerjaan seseorang maka akan memberikan kesempatan luas bagi responden untuk menerima informasi kesehatan dari lingkungan bekerja maupun fasilitas atau media informasi yang lebih maju, misalnya dengan mengikuti 
seminar tentang kesehatan ataupun penggunaan media eletronik untuk memperoleh informasi kesehatan dan hal ini dapat mendukung pengetahuan responden tentang kolostrum, karena semakin tinggi pekerjaan seseorang maka semakin banyak informasi yang diperoleh dan semakin tinggi pula pengetahuannya(15).

\section{Tingkat Pengetahuan Ibu Nifas tentang Kolostrum}

Hasil pengukuran tingkat pengetahuan ibu nifas tentang kolostrum di Rumah Sakit Panembahan Senopati Bantul dapat dilihat pada Tabel 4.

Berdasarkan Tabel 4 tersebut dapat diketahui bahwa mayoritas responden di Rumah Sakit Panembahan Senopati Bantul memiliki tingkat pengetahuan tentang kolostrum dalam kategori baik, yaitu sebesar 44 orang $(81,5 \%)$.

Pengetahuan adalah segala sesuatu yang ada di kepala kita. Kita dapat mengetahui sesuatu berdasarkan pengetahuan yang kita miiliki. Selain pengalaman, kita bisa tahu karena diberitahu oleh orang lain. Tingkat pengetahuan ibu yang baik tidak saja oleh karena ibu berpendidikan tinggi tetapi juga dipengaruhi oleh informasi yang beragam yang diperoleh ibu(16). Hal ini senada dengan hasil penelitian Nazara yang menyatakan bahwa faktor sumber informasi dapat menyebabkan ibu tidak memberikan kolostrum pada bayi baru lahir(17).

Tabel 4. Distribusi Frekuensi Tingkat Pengetahuan Ibu Nifas tentang Kolostrum di Rumah Sakit Panembahan Senopati Bantul

\begin{tabular}{lcc}
\hline Tingkat Pengetahuan & f & $\%$ \\
\hline Kurang & 0 & 0 \\
Cukup & 10 & 18,5 \\
Baik & 44 & 81,5 \\
Total & 54 & 100,0 \\
\hline
\end{tabular}

Sumber: Data Primer Tahun 2015

\section{Motivasi Pemberian Kolostrum}

Hasil penelitian terhadap motivasi pemberian kolostrum oleh ibu nifas di Rumah Sakit Panembahan Senopati Bantul disajikan pada Tabel 5.

Tabel 5. Distribusi Frekuensi Motivasi Pemberian

Kolostrum oleh Ibu Nifas di Rumah Sakit Panembahan Senopati Bantul

\begin{tabular}{lcc}
\hline Motivasi Pemberian Kolostrum & f & $\%$ \\
\hline Rendah & 0 & 0 \\
Sedang & 9 & 16,7 \\
Tinggi & 45 & 83,3 \\
Total & 54 & 100 \\
\hline
\end{tabular}

Sumber: Data Primer Tahun 2015

Berdasarkan Tabel 5 di atas sebagian besar ibu nifas di Rumah Sakit Panembahan Senopati Bantul yaitu sebanyak 45 orang $(83,3 \%)$ memiliki motivasi pemberian kolostrum termasuk dalam kategori tinggi.

Rosita menyatakan bahwa pada umumnya para ibu mau patuh dan menurut pada petugas kesehatan. Sehingga nasehat dan motivasi yang diberikan oleh tenaga kesehatan cenderung akan diikuti oleh ibu(18). Hal ini sejalan dengan penelitian Wijayanti yang menyatakan bahwa ada hubungan antara peran petugas kesehatan dengan perilaku ibu tidak memberikan kolostrum pada bayi baru lahir, dengan hasil uji statistik menunjukkan $p$-value $=0,03(19)$.

\section{Hasil Analisis Data Bivariat}

Hubungan Tingkat Pengetahuan Ibu Nifas tentang Kolostrum dengan Motivasi Pemberian Kolostrum di Rumah Sakit Panembahan Senopati Bantul

Analisis bivariat salah satunya menggunakan uji Kendall-tau. Uji ini bertujuan untuk mengetahui dan menganalisa hubungan antara variabel independen terhadap variabel dependen Tabel 6.

Tabel 6. Hubungan Tingkat Pengetahuan Ibu Nifas tentang Kolostrum dengan Motivasi Pemberian Kolostrum di Rumah Sakit Panembahan Senopati Bantul

\begin{tabular}{|c|c|c|c|c|c|c|c|c|c|c|}
\hline \multirow{3}{*}{$\begin{array}{c}\text { Motivasi } \\
\text { Pemberian } \\
\text { Kolostrum }\end{array}$} & \multicolumn{6}{|c|}{ Tingkat Pengetahuan tentang Kolostrum } & \multirow{2}{*}{\multicolumn{2}{|c|}{ Total }} & \multirow{3}{*}{$\mathbf{r}$} & \multirow{3}{*}{ p-value } \\
\hline & \multicolumn{2}{|c|}{ Baik } & \multicolumn{2}{|c|}{ Cukup } & \multicolumn{2}{|c|}{ Kurang } & & & & \\
\hline & f & $\%$ & f & $\%$ & f & $\%$ & $f$ & $\%$ & & \\
\hline Rendah & - & 0 & - & 0 & - & 0 & 0 & 0 & \multirow{4}{*}{0,632} & \multirow{4}{*}{0,000} \\
\hline Sedang & 3 & 5,6 & 6 & 11,1 & - & 0 & 9 & 16,7 & & \\
\hline Tinggi & 41 & 75,9 & 4 & 7,4 & - & 0 & 45 & 83,3 & & \\
\hline Total & 44 & 81,5 & 10 & 18,5 & 0 & 0 & 54 & 100 & & \\
\hline
\end{tabular}

Sumber: Data Primer Tahun 2015 
Hasil penelitian pada Tabel 6 menunjukkan bahwa sebagian besar ibu yang memiliki pengetahuan tentang kolostrum kategori baik mempunyai motivasi pemberian kolostrum yang tinggi yaitu sebanyak 41 orang $(75,9 \%)$, dan responden dengan tingkat pengetahuan tentang kolostrum kategori cukup mempunyai motivasi pemberian kolostrum yang sedang yaitu sebanyak 6 orang $(11,1 \%)$.

Hasil analisis statistik uji kendall tau diperoleh nilai keofisien korelasi ( $r$ ) sebesar 0,632 dan $p$-value sebesar 0,000 lebih kecil dari nilai $\alpha$ $(0,05)$. Hasil penelitian ini dapat diartikan bahwa terdapat hubungan yang signifikan antara tingkat pengetahuan ibu nifas tentang kolostrum dengan motivasi pemberian kolostrum dengan tingkat koefisien korelasi yang kuat. Hal ini senada dengan hasil penelitian Rumiyati yang menyatakan bahwa ada hubungan antara pengetahuan ibu dengan pemberian kolostrum(20).

Hasil penelitian Eni tentang Hubungan tingkat pengetahuan ibu menyusui dengan pemberian ASI pertama (kolostrum) di Rumah Bersalin An-Nissa Surakarta, menyatakan bahwa terdapat hubungan yang bermakna antara tingkat pengetahuan ibu dengan pemberian ASI pertama atau kolostrum, dengan hasil uji statistik menunjukkan $p$-value $=0,000(21)$.

\section{SIMPULAN DAN SARAN}

Sebagian besar responden penelitian berumur antara 20-35 tahun yaitu sebanyak 40 responden $(74,1 \%)$, berpendidikan SMA yaitu sebanyak 28 responden $(51,9 \%)$, dan sebagai IRT yaitu sebanyak 35 orang $(64,8 \%)$. Sebagian besar responden memiliki tingkat pengetahuan tentang kolostrum dalam kategori baik yaitu sebanyak 44 orang $(81,5 \%)$ dan memiliki motivasi pemberian kolostrum dalam kategori tinggi sebanyak 45 orang $(83,3 \%)$. Ada hubungan yang signifikan antara tingkat pengetahuan ibu nifas tentang kolostrum dengan motivasi pemberian kolostrum di Rumah Sakit Panembahan Senopati Bantul tahun 2015.

Bagi Rumah Sakit Panembahan Senopati Bantul hendaknya penelitian ini dapat dijadikan sebagai salah satu bahan dalam memberikan pendidikan kesehatan tentang kolostrum karena masih ada ibu nifas yang memiliki pengetahuan ibu tentang kolostrum dalam kategori cukup.
Peningkatan pengetahuan ibu tentang kolostrum dapat dilakukan pihak Rumah Sakit Panembahan Senopati Bantul khususnya tenaga kesehatan bidan dengan memberikan penyuluhan dan pengarahan pada ibu nifas yang semakin intensif. Bagi responden hendaknya hasil penelitian ini dapat dijadikan sumber informasi dan pengetahuan tentang pentingnya pemberian kolostrum bagi bayi. Bagi ibu nifas yang masih mempunyai pengetahuan dalam kategori cukup hendaknya menambah lagi dan mengembangkan pengetahuan yang dimiliki melalui media massa dan lain-lain.

\section{RUJUKAN}

1. Depkes RI. Profil Kesehatan Indonesia 2008. Jakarta: Departemen Kesehatan Republik Indonesia; 2009.

2. Manuaba. IImu Kebidanan Penyakit Kandungan dan Keluarga Berencana. Jakarta: EGC; 2006.

3. Prasetyono DS. Buku Pintar ASI Eksklusif. Yogyakarta: Diva Press; 2005.

4. Umniyati H. Penerapan ASI Eksklusif 6 Bulan Versus Pemberian Makanan Pendamping ASI Dini Di Indonesia. J Kedokteran Yarsi. 2005;1(13):131-7.

5. Kemenkes RI. Profil Kesehatan Indonesia 2012. Jakarta: Kementrian Kesehatan RI; 2012.

6. Dinkes DIY. Profil Kesehatan Propinsi DIY 2012. Yogyakarta: Dinkes DIY; 2013.

7. Dinkes Bantul. Profil Kesehatan Kabupaten Bantul Tahun 2014. Yogyakarta: Dinkes Kabupaten Bantul; 2014.

8. Roesli. Inisiasi Menyusu Dini Plus ASI Eksklusif. Jakarta: Pustaka Bunda; 2008.

9. Hayati AW. Buku Saku Gizi Bayi. Jakarta: EGC; 2009.

10. Februhartanty J. ASI dari Ayah untuk Ibu dan Bayi. Jakarta: Semesta Media; 2009.

11. Notoatmojo S. Metodologi Penelitian Kesehatan. rev ed. Jakarta: Rineka Cipta; 2005.

12. Kusmayanti. Gambaran Tingkat Pengetahuan Ibu Nifas tentang ASI Eksklusif di Ruang Nifas RS Sariningsih. Unpublished. Bandung; 2005.

13. Notoatmojo S. IImu Perilaku Kesehatan. Jakarta: Rineka Cipta; 2010.

14. Tarigan EP, Erniyati. Pemberian Kolostrum Pada Suku Karo di Desa Sukanalu Kecamatan Barusjahe Kabupaten Karo [internet]. 2011 [cited 
2015 Feb 15]. Available from: http://download. portalgaruda.org/article. php?article $=59066$ \&val=4132.

15. Wawan A, Dewi. Teori dan Pengukuran Pengetahuan, Sikap, dan Perilaku Manusia. Yogyakarta: Nuha Medika; 2010.

16. Prasetya B. Metodologi Penelitian Kuantitatif. Jakarta: PT. Raja Grafindo; 2007.

17. Nazara P. Faktor-Faktor yang Menyebabkan Ibu Tidak Memberikan Kolostrum Kepada Bayi Baru Lahir Di Desa Sifalaete Ulu Kecamatan Gunungsitoli Kabupaten Nias Tahun 2007. D IV Bidan Pendidik USU; 2007.

18. Rosita S. ASI untuk Kecerdasan Bayi. Yogyakarta: Ayyana; 2008.
19. Wijayanti AR, et al. Faktor-Faktor yang berhubungan dengan Perilaku Ibu tidak memberikan Kolostrum kepada Bayi Baru Lahir [internet]. 2012 [cited 2015 Jan 19]. Available from: http://online-journal.unja.ac.id/index.php/ kedokteran/article/ view/1011/830.

20. Rumiyati. Hubungan Tingkat Pengetahuan Ibu Menyusui dengan Pemberian ASI Pertama (Kolostrum) di Rumah Bersalin An-Nissa Surakarta. DIV Kebidanan. FK Universitas Sebelas Maret; 2008.

21. Eni R. Hubungan Tingkat Pengetahuan Ibu Menyusui dengan Pemberian ASI Pertama (Kolostrum) di Rumah Bersalin An-Nissa Surakarta. J Kesmadaska. 2011;2(2):30-34. 